\title{
Pengaruh Model Talking Stick terhadap Hasil Belajar IPS Siswa SD
}

\author{
Oktaviastuti Awalia Fajrin \\ PGSD Universitas Kristen Satya Wacana \\ 292015106@student.uksw.edu
}

\begin{abstract}
Abstrak
Penelitian ini bertujuan untuk mengetahui peningkatan hasil belajar IPS siswa Sekolah Dasar. Model Talking Stick dapat melatih peserta didik untuk berpikir kritis, mengajarkan peserta didik untuk memahami materi pelajaran dengan cepat, melatih siswa agar giat belajar, melatih siswa untuk bertanya dan mengungkapkan pendapat. Selain itu dengan menggunakan model Talking Stick pembelajaran menjadi lebih menyenangkan, sehingga hasil belajar peserta didik terutama pada mata pelajaran IPS menjadi optimal atau meningkat. Penelitian ini menggunakan metode studi dokumen atas hasil penelitian sebelumnya atau disebut dengan metaanalisis. Penelususran data dilakukan melalui Google Cendekia dan diperoleh 10 jurnal terpublikasi. Hasil penelitian menunjukkan bahwa dengan menggunakan model pembelajaran Talking Stick efektif untuk meningkatkan hasil belajar peserta didik khususnya pada siswa Sekolah Dasar. Hasil belajar pada mata pelajaran IPS dengan menggunakan model Talking Stick mengalami peningkatan jika dibandingkan dengan model pembelajaran konvensional. Jika dengan model Talking Stick masih kurang meningkatkan hasil belajar peserta didik, maka solusi yang lain adalah guru dapat menyesuaikan model pembelajaran yang ada dengan kondisi dan kebutuhan peserta didik.
\end{abstract}

Kata Kunci: pembelajaran IPS, Talking Stick, dan hasil belajar IPS

\begin{abstract}
This study aims to determine the increase in learning outcomes of primary school students. The Talking Stick model can train learners to think critically, teach students to understand the subject matter quickly, train students to study hard, train students to ask questions and express opinions. In addition, by using the Talking Stick model of learning becomes more fun, so the learning outcomes of learners, especially on IPS subjects to be optimal or increased. Is the Talking Stick model effective for improving learners' learning outcomes on social studies subjects? This research used document study method of previous research result or called metaanalysis. Data search is done through Google Scholar and obtained 10 published journals. The results showed that by using Talking Stick learning model is effective to improve learning outcomes of students especially in elementary school students. The learning outcomes in IPS subjects using the Talking Stick model have improved when compared with conventional learning models. If the Talking Stick model is still less improve the learners' learning outcomes, then the other solution is the teacher can adjust the existing learning model to the conditions and needs of learners.
\end{abstract}

Keywords: IPS learning, Talking Stick, and IPS learning outcomes 


\section{PENDAHULUAN}

Pendidikan adalah usaha sadar yang dilakukan oleh pendidik untuk mewujudkan suasana belajar dan proses pembelajaran agar peserta didik lebih aktif dalam mengembangkan potensi diri, kecerdasan, kepribadian, akhlak mulia, dan keterampilan yang diperlukan ketika di masyarakat. Menurut Undang-undang Pendidikan No. 20 Tahun 2003 Tentang Sistem Pendidikan Nasional, Tujuan Pendidikan Nasional adalah untuk mengembangkan potensi yang dimiliki peserta didik agar menjadi manusia yang bertaqwa kepada Tuhan Yang Maha Esa, berilmu, berakhlak mulia, kreatif, mandiri, menjadi warga negara yang demokratis serta peka terhadap tantangan zaman yang semakin modern. Pendidikan khususnya di Sekolah Dasar disesuaikan dengan tingkat perkembangan peserta didik, sehingga potensi yang dimiliki peserta didik dapat terasah dengan baik. Pengembangan potensi peserta didik yang kreatif, berilmu, mandiri, dan menjadi warga negara yang demokratis dapat dicapai melalui mata pelajaran di sekolah yaitu mata pelajaran IPS (Ilmu Pengetahuan Sosial).

Ilmu Pengetahuan Sosial (IPS) merupakan salah satu mata pelajaran yang diajarkan di Sekolah Dasar. Mata pelajaran IPS akan berguna bagi peserta didik dalam bermasyarakat, menghadapai tantangan zaman dan permasalah sosial. Karena mata pelajaran IPS sangat berguna, maka dari itu guru harus mempersiapkan materi yang akan diajarkan kepada peserta didik dengan baik. Namun fakta yang ada, guru belum mampu menjalankan tanggung jawabnya dalam meningkatkan kualitas sember daya manusia. Selain itu kebanyakan guru juga belum siap dalam menyiapkan dan menyajikan materi IPS yang akan diberikan kepada peserta didik. Guru juga kurang menguasai mata pembelajaran IPS yang memiliki materi dan wawasan yang luas. Hal tersebut menyebabkan hasil belajar siswa khususnya pada mata pelajaran IPS kurang optimal. Dalam belajar mengajar di kelas peserta didik hanya menerima materi yang disampaikan oleh guru dengan metode ceramah. Peserta didik masih cenderung pasif dan menunggu informasi maupun pertanyaan dari guru.

Dalam mengajar guru kurang kurang mengajak peserta didik untuk belajar sambil bermain. Peserta didik hanya datang dan duduk di kelas mendengarkan guru ceramah, sehingga menyebabkan peserta didik mengantuk dalam menangkap 
pembelajaran IPS. Guru yang hanya berceramah dalam mengajar juga menyebabkan pembelajaran menjadi membosankan dan menjadikan waktu pembelajaran menjadi terasa lama. Guru juga jarang memberikan peluang kepada peserta didik untuk belajar dengan berdiskusi dalam kelompok.

Selain itu guru kurang kreatif dalam memilih dan mengembangkan metode atau model pembelajaran yang sesuai dengan kegiatan pembelajaran khususnya pada mata pelajaran IPS. Sehingga kegiatan pembelajaran menjadi membosankan dan kurang menarik. Hal itu disebabkan karena guru kurang dapat mengembangkan dan memanfaatkan sumber belajar yang dimiliki sekolah, seperti buku-buku di perpustakaan, internet, dan lingkungan sekitar.

Untuk itu perlu adanya solusi yang tepat untuk mengatasi permasalahanpermasalah dalam kegiatan belajar mengajar di sekolah. Solusinya adalah dengan mengganti metode atau model pembelajaran yang biasanya terpusat pada guru (teacher center), diubah dengan model pembelajaran yang inovatif dan berpusat pada siswa (student center), seperti dengan menggunakan model pembelajaran kooperatif tipe Talking Stick (tongkat berbicara). Model ini menuntut peserta didik untuk aktif, berani berbicara dan mengemukakan pendapat, sehingga memudahkan peserta didik dalam mengingat pelajaran yang sudah diajarkan. Model talking stick dilakukan dengan pemberian tongkat oleh guru secara acak yang ditujukan kepada peserta didik, untuk itu peserta didik harus siap dalam menjawab pertanyaan atau mengemukakan pendapat.

Talking Stick merupakan model pembelajaran yang dapat mendorong peserta didik untuk berani mengemukakan pendapat. Model pembelajaran ini menggunakan bantuan alat berupa tongkat, dimana jika peserta didik yang menerima tongkat harus berani menjawab pertanyaan dari guru dan mengemukakan pendapatnya. Menurut Suyatno (2009: 71) sintak model pembelajaran Talking Stick yaitu: (1) pemberian informasi pembelajaran secara umum, (2) peserta didik dibagi menjadi beberapa kelompok, (3) pemilihan ketua dan pembagian tugas oleh anggota kelompok untuk membahas materi tertentu, (4) peserta didik bekerja dalamkelompnya, (5) tiap kelompok membuat pertanyaan seputar materi yang didapat dan soal yang dibuat diberikan kepada kelompok lain, (6) kelompok lain menjawab secara bergantian menggunakan alat berupa tongkat 
yang digulirkan secara acak, (7) peserta didik menyimpulkan materi yang sudah dipelajari, dan (8) kegiatan refleksi dan evaluasi pembelajaran.

Menurut Kurniasih (2015) menerangkan bahwa kelebihan dari model talking stick yaitu: melatih keterampilan peserta didik dalam memahami materi yang sudah diajarkan dengan cepat, menguji kesiapan peserta didik dalam memahami dan menguasai materi pelajaran yang sudah diajarkan, melatih peserta didik untuk giat belajar karena peserta didik harus siap menjawab atau mengemukakan pendapat jika menerima tongkat, memudahkan peserta didik dalam mengingat pelajaran khusunya mata pelajaran IPS, menyisipkan unsur permainan sehingga pembelajaran terasa menyenangkan dan tidak membosankan.

\section{METODE PENELITIAN}

Penelitian ini menggunakan studi dokumen hasil penelitian sebelumnya atau disebut dengan meta-analisis. Pengumpulan data dilakukan dengan menulusuri jurnal pada beberapa media elektronik seperti digital library dan internet. Penelusuran jurnal dilakukan melalui Google Cendekia, dan kata kunci yang digunakan untuk penelusuran jurnal adalah: pembelajaran IPS, Talking Stick, dan hasil belajar IPS. Dari hasil penelusuran diperoleh data yang memenuhi kriteria, yaitu tersedianya data berupa nama peneliti, tahun penelitian dan hasil penelitian dalam bentuk deskripsi. Diperoleh penelitian yang ditebitkan di Jurnal Nasional, dari hasil penelitian itu dipilih Ni Luh Kd. Dwi Pradnyani, I Wyn. Sujana, \& Ni Wyn. Suniasih (2013), Vegita Yulia Wardani (2017), Ayu Pratiwi Kusuma Wardhani (2017), Likus, Suhardi Merli \& Sri Utami (2017), Eliana Yunitha Seran (2016), I.G.A Mas Dewi Anggarini, I Wyn. Sujana \& I. B. Gd. Suryaabadi (2013), Sylvia Fransiska Siregar, Otang Kurniawan \& Eddy Noviana (2016), Ni Ketut Triati Lestari, Mg. Rini Kristiantari \& Ni Nyoman Ganing (2018), Basilisa Nuari Deana Amoy, Sugiyono \& Syamsiati (2014), Norliza, Lazim, Eddy Noviana (2018).

\section{HASIL DAN PEMBAHASAN}

Penelitian ini menggunakan studi dokumen dari hasil-hasil penelitian sebelumnya. Pengumpulan data dalam penelitian dengan cara melakukan 
penelusuran beberapa jurnal dengan Google Cendekia. Kata kunci yang digunakan untuk penelusuran adalah “Talking Stick Terhadap Hasil Belajar IPS”. Dari hasil penelusuran diperoleh 10 artikel junal terpublikasi dan memiliki kriteria yang sama. Analisis menggunakan metode perbandingan untuk mnentukan efektifitas Penerapan Model Talking Stick Terhadap Hasil Belajar IPS.

Berdasarkan hasil penelusuran yang dilakukan dengan menggunakan Google Cendekia terseleksi seperti di atas, hasil analisis terkait Penerapan Model Talking Stick Terhadap Hasil Belajar IPS dapat diperiksa berikut ini.

Hasil penelitian Dwi (2013); Vegita (2017); Likus (2017); Eliana (2016); Syilvia (2016); Lestari (2018); Basilisa (2014) dan Norliza (2018) menjelaskan bahwa dengan menerapkan model pembelajaran Kooperatif tipe Talking Stick efektif untuk meningkatkan hasil belajar khususnya pada mata pelajaran IPS di Sekolah Dasar. Menurut Ayu (2017) dan Anggarini (2013), menjelaskan bahwa rata-rata belajar siswa kelas $\mathrm{V}$ lebih tinggi dengan menggunakan model Talking Stick daripada menggunakan model pembelajaran konvensional.

Dari sepuluh hasil penelitian yang terpublikasi dalam Jurnal Nasional ternyata Penerapan Model Pembelajaran Kooperatif Tipe Talking Stick terbukti efektif untuk meningkatkan hasil belajar pada mata pelajaran IPS (Ilmu Pengetahuan Sosial). Kefektifan ini terjadi karena model pembelajaran Talking Stick lebih menyenangkan dan membuat peserta didik aktif dibandingkan dengan model pembelajaran konvensional.

Penerapan model pembelajaran kooperatif tipe Talking Stick adalah sebagai berikut. Guru menjelaskan materi tentang IPS. Kemudian guru membentuk kelas menjadi beberapa kelompok untuk mengerjakan tugas yang akan diberikan oleh guru. Siswa bersama dengan kelompoknya mengerjakan tugas dengan teliti, bertanggung jawab dan jujur. Setelah siswa mengerjakan tugas dengan kelompoknya, kemudian guru akan menguji pengetahuan individu siswa dengan bantuan alat berupa tongkat. Tongkat tersebut akan dgulirkan ke setiap siswa, jika siswa menerima tongkat tersebut maka wajib menjawab pertanyaan dari guru. Pertanyaan yan diberikan seputar materi IPS yang telah dijelaskan guru. Permainan tongkat haruslah menyenangkan dan dapat diselingi permainan dalam kegiatan pembelajaran, sehingga siswa akan merasa lebih senang ketika belajar 
dan tidak merasa bosan. Model pembelajaran Talking Stick sesuai dengan karakteristik siswa Sekolah Dasar, karena siswa SD senang belajar sambil bermain. Apabila siswa sudah merasa nyaman dan senang ketika belajar, maka motivasinya akan meningkat. Hal itu akan menyebabkan hasil belajar yang diperoleh akan meningkat dan optimal.

Jika dengan menggunakan model Talking Stick tidak menyebabkan meningkatnya hasil belajar, maka solusi yang lain adalah guru dapat menyesuaikan model pembelajaran yang digunakan dengan kondisi dan kebutuhan siswa. Model pembelajaran untuk Kurikulum 2013 sangat banyak dan beragam. Model pembelajaran Kooperatif sendiri memiliki banyak tipe, seperti Model STAD, Jigsaw, Group Investigation, Make a Match, TGT dan masih banyak lagi. Untuk itu guru harus cermat dalam memilih dan menggunakan model pembelajaran yang cocok ketika mengajar.

\section{KESIMPULAN DAN SARAN}

Berdasarkan analisis hasil-hasil penelitian terdahulu yang dapat dipercaya kebenarannya, bahwa Penerapan Model Pembelajaan Talking Stick teruji efektif untuk meningkatkan hasil belajar IPS khususnya di Sekolah Dasar. Jika dibandingkan dengan menggunakan model pembelajaran konvensional, model talking stick lebih meningkatkan dan mengoptimalkan hasil belajar Ilmu Pengetahuan Sosial. Dalam mengajar guru harus cermat dalam memilih dan menggunakan model pembelajaran apa yang cocok dalam mengajar, sehingga peserta didik lebih mudah menangkap pembelajaran dan meingkatkah hasil belajar di sekolah. Guru dalam kegiatan pembelajaran dapat menggunakan model pembelajaran Talking Stick untuk meningkatkan hasil belajar siswa.

\section{DAFTAR PUSTAKA}

Amoy, B. N. D. (2014). Pengaruh Model Kooperatif Tipe Talking Stick terhadap Hasil Belajar Peserta Didik Kelas V Sekolah Dasar. Jurnal Pendidikan dan Pembelajaran, $3(12)$.

Anggarini, I. M. D., Sujana, I. W., \& Suryaabadi, I. G. (2013). Pengaruh Model Pebelajaran Kooperatif Talking Stick Berbasis Aneka Sumber Terhadap Hasil Belajar IPS Siswa Kelas V SD Negeri 5 Dalung. MIMBAR PGSD Undiksha, 1(1).

Damayanti, N. K. I., Sanjaya, D. B., \& Suastika, I. N. (2017). Implementasi Model Pembelajaran Talking Stick untuk Meningkatkan Motivasi, Aktivitas dan Hasil 
Belajar Siswa Kelas VIII B8 SMP Negeri 6 Singaraja dalam Pembelajaran Pendidikan Kewarganegaraan Tahun Pelajaran 2016/2017. Jurnal Pendidikan Kewarganegaraan Undiksha, 8(2).

Depdiknas. 2003. Undang-undang RI No. 20 tahun 2003 tentang sistem pendidikan nasional. Jakarta: Depdiknas

Kurniasih, Imas dan Berlin Sani. 2015. Ragam Pengembangan Model Pembelajaran: Untuk Peningkatan Profesionalitas Guru. Cetakan Ke-1. Jakarta: Kata Pena.

Lestari, N. K. T., Kristiantari, M. R., \& Ganing, N. N. (2018). Pengaruh Model Pembelajaran Talking Stick Berbantuan Lagu Daerah Terhadap Hasil Belajar IPS. International Journal of Elementary Education, 1(4), 290-297.

Likus, L., Marli, S., \& Utami, S. Pengaruh Model Talking Stick Terhadap Hasil Belajar IPS Siswa Kelas III. Jurnal Pendidikan dan Pembelajaran, 7(3).

Mailani, N. L. A. (2013). Peningkatan Motivasi dan Hasil Belajar Siswa VII-5 SMP Lab Undiksha Singaraja Melalui Model Talking Stick. Widya Winayata: Jurnal Pendidikan Sejarah, 1(1).

Norliza, N., \& Noviana, E. (2018). Penerapan Model Pembelajaran Kooperatif Tipe Talking Stick untuk Meningkatkan Hasil Belajar IPS Siswa Kelas IV SDN 49 Tameran Kecamatan Bengkalis. Jurnal Online Mahasiswa (JOM) Bidang Keguruan dan Ilmu Pendidikan, 4(1), 1-13.

Pradnyani, N. L. K. D., Sujana, I. W., \& Suniasih, N. W. (2013). Pengaruh Penerapan Model Pembelajaran Kooperatif Tipe Talking Stick Terhadap Hasil Belajar Ips Siswa Kelas 4 SDN 2 Sesetan Denpasar. MIMBAR PGSD Undiksha, 1(1).

Puspitawangi, K. R., Wibawa, I. M. C., \& Pudjawan, K. (2016). Pengaruh Model Pembelajaran Kooperatif Tipe Talking Stick Berbantuan Media Audio Terhadap Hasil Belajar IPS Siswa. MIMBAR PGSD Undiksha, 4(1).

Santiasih, N. L. A., Ganing, N. N., \& Sujana, I. W. (2016). Penerapan Talking Stick Dalam Pendekatan Saintifik untuk Meningkatkan Penguasaan Kompetensi Pengetahuan IPS dan Motivasi Belajar. MIMBAR PGSD Undiksha, 4(1).

Sari, S., \& Wijayanti, A. (2017). Talking Stick: Hasil Belajar IPA dan Kemampuan Kerjasama Siswa. WACANA AKADEMIKA: Majalah Ilmiah Kependidikan, 1(2).

Seran, E. Y. (2016). Pengaruh Model Pembelajaran Talking Stick terhadap Hasil Belajar Siswa Pada Mata Pelajaran Ilmu Pengetahuan Sosial Terpadu (Studi Eksperimen Kelas IV Sekolah Dasar Negeri No. 01 Kenukut Tahun Pelajaran 2013/2014). VOX EDUKASI, 4(1), 21-36.

Shoimin, Aris.2014.68 Model Pembelajaran Inovatif dalam Kurikulum 2013. Jakarta:ARRuzz Media Susanto,

Siregar, S. F. S. F., Kurniaman, o. K. O., \& noviana, e. N. E. (2016). Penerapan Model Pembelajaran Kooperatif Tipe Talking Stick untuk Meningkatkan Hasil Belajar IPS Siswa Sekolah Dasar (Studi Eksperimen Kelas V SD Negeri 163 Pekanbaru. Jurnal Online Mahasiswa (JOM) Bidang Keguruan dan Ilmu Pendidikan, 3(1), 1-14.

Suyatno. 2009. Menjelajah Pembelajaran Inovatif. Surabaya: Pers Media Buana Pustaka.

WardanI, V. Y. Perbedaan Hasil Belajar Ips Dengan Menggunakan Model Pembelajaran Kooperatif Tipe Talking Stick Pada Siswa Kelas IV SD Negeri 2 Kampung Baru. 